\title{
A puerperal haemorrhagic state due to a heparin-like anticoagulant
}

\author{
M. L. N. WILLOUGHBY
}

From the Department of Haematology, Southern General Hospital, Glasgow

SYNOPSIS The occurrence of a severe generalized haemorrhagic state in an obstetric case due to a heparin-like anticoagulant is described. This appeared in the post-partum period apparently following a compatible blood transfusion. The pattern of results found in conventional laboratoryi tests for elucidating acute blood coagulation disorders is described, and the distinction between $\vec{B}$ heparinaemia and the defibrination syndrome emphasized.

Protamine sulphate corrected the clotting abnormality in vitro and when administered in amounts? so as to achieve a similar concentration in vivo was followed by correction of the blood coagulation and the sudden cessation of bleeding from multiple sites.

The defibrination syndrome has become well recognized as an important and treatable cause of acute generalized haemorrhagic states developing in the perinatal period (Schneider, 1951; Soulier, Alagille, and Larrieu, 1956). Simple and rapid laboratory or bed-side tests have been proposed for confirming the diagnosis (Sharp, Howie, Biggs, and Methuen, 1958; Hardisty, 1958; Ingram and Matchett, 1960).

Other types of acute coagulation disorders associated with pregnancy are less common and include unexplained vitamin $\mathrm{K}$ deficiency (Larsen, 1960), circulating anticoagulants affecting the early stages of blood coagulation (Hougie, 1955), and increased heparin-like activity of the blood (Ratnoff and Vosburgh, 1952; Jürgens and Stein, 1954; Masure and Schockaert, 1954). Ingram, Norris, and Tanner (1960) have drawn attention to the fact that heparinaemia may cause difficulty in the laboratory diagnosis of acute coagulation disorders. The present case is reported because it endorses this view and emphasizes the importance of distinguishing this state from the more commonly occurring defibrination syndrome. Providing heparinaemia is recognized intravenous protamine sulphate appears to be a simple and effective treatment. Greater awareness of its possible occurrence is therefore desirable.

\section{LABORATORY METHODS}

The thrombin clotting-time and fibrinogen titre (thrombin titre) were performed as described by Sharp et al. (1958).

Received for publication 13 August 1962.
The thromboplastin generation screening test was that of Hicks and Pitney as described by Ingram (1961). The immunological test for fibrinogen (Fi test of Baxter Ltd. was performed as described by the makers. Other coagu lation tests were performed as described by Biggs an Macfarlane (1957).

\section{CASE HISTORY AND LABORATORY FINDINGS}

The patient was a primigravida of 29 years. There was nథ past or family history of a bleeding tendency. In the 28tị. week of pregnancy she was admitted to hospital for treatment of pre-eclamptic toxaemia. This rapidly settled with sedatives and a low-salt diet, but she was noted to have chronic sinusitis and occasional bronchospasm? The haemoglobin was $10.4 \mathrm{~g} . \%$ without evidence of macrocytosis. Her blood group was A Rh negative and no $\mathrm{Rh}$ antibodies were detected. She was discharged to her own doctor's care but was readmitted at the 43r week for post-maturity. Spontaneous labour began but mid-cavity forceps were applied because of foetaf. distress. There was no undue blood loss and the placents with membranes were completely delivered. The baby made uneventful progress.

On the second day after delivery she was given a blooe transfusion for anaemia. After completion of the second bottle she developed a pyrexia of $104^{\circ} \mathrm{F}$. and a pulse rate of 140 per minute. There was no rigor. Intramuscular phenergan $(50 \mathrm{mg}$.) was given. Moderately severe vagina\$ bleeding began two hours later (at 2.00 a.m.) and was not controlled by ergometrine. The blood did not appear to be clotting and venepuncture sites started to bleed. A 4 a.m. a sample of citrated plasma was examined. Thi 9 was not clotted by thrombin when tested neat or dilute $\$$ 1 in 2 with saline although on further dilution it produce clots up to a dilution of 1 in 128. The Quick prothrombi 
time was over 3 minutes. The Fi test for afibrinogenaemia gave a normal result. The patient was given further blood transfusion, $4 \mathrm{~g}$. of fibrinogen, $10 \mathrm{mg}$. of vitamin $\mathrm{K}_{1}$, and $6 \mathrm{~g}$. orally of epsilon-aminocaproic acid (E.A.C.A.) with the object of inhibiting possible fibrinolysis (Nilsson, Sjoerdsma, and Waldenström, 1960).

Bleeding from the vagina and venepuncture sites continued and fresh-frozen plasma was given. It was impossible to use a sphygmomanometer cuff because of accentuation of the bleeding from venepuncture sites. At 10.00 a.m. further samples of blood were collected and hysterectomy was undertaken in an attempt to control the uterine haemorrhage. Capillary bleeding was troublesome during the operation making it difficult to identify all bleeding points. Further fibrinogen $(4 \mathrm{~g}$.) and continuous blood transfusion was given. Post-operatively the patient was very collapsed, and bleeding from the operation wound, vagina, episiotomy wound, and venepuncture sites continued. The haematological findings at 10.00 a.m. are shown in Table I. It became appreciated that these could be explained by a circulating anticoagulant, and further experiments confirmed this (Table II). Also it was found that the addition of protamine sulphate to the patient's plasma $(0.1 \mathrm{mg} . / \mathrm{ml}$.) reduced its clottingtime with thrombin from infinity to normal (10 seconds)

TABLE I

LABORATORY FINDINGS BEFORE PROTAMINE THERAPY

Haemoglobin (g./100 ml.) $7 \cdot$

White cell count (per c.mm.) 2.000
Platelet count (per c.mm.)

Blood film

Clotting time

Prothrombin time

Fibrinogen titre

Thrombin clotting time

\section{0,000}

Marked neutropenia with many of the remaining neutrophils showing degenerative changes. No spherocytes found

More than $3 \mathrm{hr}$. (normal 6-10 min.) More than $5 \mathrm{~min}$. (normal $13 \mathrm{sec}$.) Titre $1: 128$ (normal $1: 64$ to $1: 128$ )

More than $1 \mathrm{hr}$. (normal 9-15 sec.)

Protamine sulphate added in a concentration of $0.1 \mathrm{mg} . / \mathrm{ml}$. of patient's plasma, shortened the thrombin clotting-time to $\mathbf{1 0}$ seconds.

and greatly shortened the prothrombin time (Table II). These experiments were not elegantly planned, being performed in considerable haste and using reagents that were readily available. Treatment with protamine sulphate was suggested in a dosage of approximately $30 \mathrm{ml}$. of the $1 \%$ solution intravenously. This was given slowly and after $25 \mathrm{ml}$. had been given the bleeding from all sites stopped dramatically (3.15 p.m.). The patient's general condition also improved (pulse 120 per minute, blood pressure $120 / 70 \mathrm{~mm}$. $\mathrm{Hg}$ ).

Ten hours later bleeding from the vagina and abdominal wound started again. Further protamine sulphate was given in two separate doses of $10 \mathrm{ml}$. but without halting the bleeding. A sample of blood was tested at 3.30 a.m. (Table III). This showed that coagulation was nearly normal, but there was an indication for giving a further $30 \mathrm{ml}$. of protamine and also some fresh frozen plasma. Bleeding continued and it was thought to be arising from a local bleeding point. The abdomen was re-opened and a bleeding point in the left ovarian ligament was found.

\section{TABLE III}

LABORATORY FINDINGS 12 HOURS AFTER INITIAL PROTAMINE THERAPY

\begin{tabular}{ll}
\hline Platelet count (per c.mm.) & 40,000 \\
Clotting time & $10 \mathrm{~min} .$, solid clots formed \\
Prothrombin time & $15 \mathrm{sec}$. \\
Fibrinogen titre & $1: 128$ (normal) \\
Thrombin clotting time & Neat plasma, $18 \mathrm{sec}$. \\
& 1 in 2 plasma, diluted with saline, 15 sec. \\
& 1 in 2 plasma, diluted with protamine, \\
& $7 \mathrm{sec}$. \\
$\begin{array}{l}\text { Thromboplastin generation } \\
\text { screening test }\end{array}$ & $\begin{array}{l}15 \mathrm{sec} \text {, normal 10 sec., slightly im- } \\
\text { paired, suggesting deficiency of factor V } \\
\end{array}$ \\
& or AHG
\end{tabular}

Complete haemostasis was then obtained and the wound closed. By this time the patient had received 20 pints of blood and $30 \mathrm{ml}$. of $10 \%$ calcium gluconate.

Repeated aspiration of the bronchial tree was necessary. During bronchoscopy at the end of the operation cardiac arrest occurred. Cardiac massage resulted in a return of normal rhythm. Subsequently it became impossible to achieve adequate oxygenation of the lungs and the patient died two hours later despite all efforts at resuscitation.

Full grouping, compatibility, and bacteriological examination of the bottles from the initial blood transfusion failed to show any abnormality, and there was never any evidence of intravascular haemolysis. Necropsy failed to throw light on the cause of the haemorrhagic state. There was no evidence of renal tubular damage or haemorrhage into a vital organ.

TABLE II

PROTHROMBIN TIME ON MIXTURES OF PATIENT'S PLASMA WITH NORMAL PLASMA OR PROTAMINE ${ }^{1}$ Inhibitory Effect Protamine Effect

\begin{tabular}{|c|c|c|c|c|c|c|c|c|c|c|c|c|c|}
\hline Patient's plasma (citrated) & $\mathbf{0}$ & 1 & 2 & 5 & 8 & 10 & $\mathbf{0}$ & 5 & 4 & 5 & 6 & 8 & 9 \\
\hline Normal plasma (citrated) & 10 & 9 & 8 & 5 & 2 & 0 & 5 & $\mathbf{0}$ & $\mathbf{0}$ & $\mathbf{0}$ & $\mathbf{0}$ & 0 & $\mathbf{0}$ \\
\hline Protamine $(100 \mu \mathrm{g} . / \mathrm{ml}$. in saline) & 0 & $\mathbf{0}$ & $\mathbf{0}$ & $\mathbf{0}$ & $\mathbf{0}$ & $\mathbf{0}$ & $\mathbf{0}$ & $\mathbf{0}$ & 6 & 5 & 4 & 2 & 1 \\
\hline Saline $(0.85 \%)$ & $\mathbf{0}$ & $\mathbf{0}$ & $\mathbf{0}$ & 0 & 0 & $\mathbf{0}$ & 5 & 5 & 0 & $\mathbf{0}$ & $\mathbf{0}$ & 0 & $\mathbf{0}$ \\
\hline 'Prothrombin time' of mixture (sec.) & 13 & 15 & 20 & 150 & $300+$ & $300+$ & 38 & $300 \div$ & 43 & 75 & $300+$ & $300+$ & $300 \div$ \\
\hline
\end{tabular}

'The figures indicate the proportion by parts of the different components in each mixture.

Of the mixture, $0.1 \mathrm{ml}$, $+0.1 \mathrm{ml}$. of a saline suspension of brain were warmed at $37^{\circ} \mathrm{C}$. and recalcified with $0.1 \mathrm{ml}$. of pre-warmed $0.025 \mathrm{M}$ $\mathrm{CaCl}_{2}$. The clotting-time of the mixture was recorded. 


\section{DISCUSSION}

The initial laboratory findings of indefinitely prolonged whole-blood clotting time, very long prothrombin time, and the failure of neat or 1 in 2 citrated plasma to clot with thrombin raised the possibility of a fibrinogen deficiency or fibrinolysis. This diagnosis appeared to fit the clinical picture of severe post-partum haemorrhage. Fibrinogen ( 4 g.) and E.A.C.A. ( 6 g. by mouth) were given but without benefit. Further tests on the original plasma unexpectedly showed that serial dilutions in saline produced normal clot formation with thrombin, i.e., between dilutions of 1 in 4 and 1 in 128, although neat or 1 in 2 plasma could not be clotted by the similar addition of thrombin. This result suggested that an inhibitor was present in the patient's plasma, which became inactive on dilution. When a 1 in 2 dilution of patient's plasma in a solution of protamine $(100 \mu \mathrm{g} . / \mathrm{ml}$.) was tested with thrombin a normal clotting-time was found, indicating that the inhibitor was fully neutralized by this amount of protamine and was 'heparinoid' in nature.

A similar conclusion was reached from investigation of the cause of the prolonged prothrombin time. Adding 2 parts of the patient's plasma to 8 parts of normal plasma caused a significant prolongation of the prothrombin time of the mixture, indicating the presence of an inhibitor. Also the prothrombin time was corrected by protamine in the same concentration as that in the thrombin time test above (Table III). From this it was deduced that approximately $100 \mu \mathrm{g}$. protamine $/ \mathrm{ml}$. of the patient's plasma should be required in vivo. Assuming a plasma volume of approximately 3 litres this would be equivalent to $300 \mathrm{mg}$. or $30 \mathrm{ml}$. of the $1 \%$ solution available. After about $25 \mathrm{ml}$. had been slowly given the patient stopped bleeding an $\vec{b}$ remained clinically well for 10 hours, suggesting that: the results in vitro closely reflected the state in vivo

In view of the unusual pattern of results found iro the fibrinogen titre test a model experiment has beero set up using various levels of heparin in plasma⿳亠 The results are shown in Table IV, where they are contrasted with those in four cases of the defibrina tion syndrome due to accidental obstetrical hae $=$ morrhage. Similar results to those shown in Table IP were obtained in a model experiment by substituting $\overrightarrow{\vec{H}}$ heparinized (10 units $/ \mathrm{ml}$.), platelet-poor normaw citrated plasma for the patient's plasma. Hepari in this concentration also caused indefinite pro $=$ longation of the whole-blood clotting time. These findings suggest that the anticoagulant in the patient's plasma was heparin-like in nature.

Concomitant fibrinogen deficiency or significane fibrinolysis was excluded in this case by the normal fibrinogen titre (1 in 128) and lack of lysis aftez 24 hours' incubation in the three specimens testeo (including one taken before treatment). Also it is of interest that an immunological test for fibrinogere (Fi test of Baxter Ltd.) gave a normal resultc Thrombocytopenia was absent initially $(170,000 \dot{b}$ c.mm.) but appeared $(40,000 /$ c.mm.) after 20 pint? of blood had been given in 36 hours. This can be attributed to the effect of transfusion (Krevans and Jackson, 1955).

The exclusion of significant fibrinolysis of fibrinogen deficiency is of interest since a substance antithrombin VI, may be released during fibrino 3 genolysis (Niewiarowski and Kopec, 1961) whict inhibits the thrombin-fibrinogen reaction and can be neutralized by protamine. For complete neutralio zation, however, very large amounts of protamine are needed, i.e., $1.25 \mathrm{mg} . / \mathrm{ml}$. of plasma, or more

TABLE IV

RESULTS OF FIBRINOGEN TITRE IN PATIENT, HEPARINIZED PLASMA, AND IN CASES OF DEFIBRINATION SYNDROME

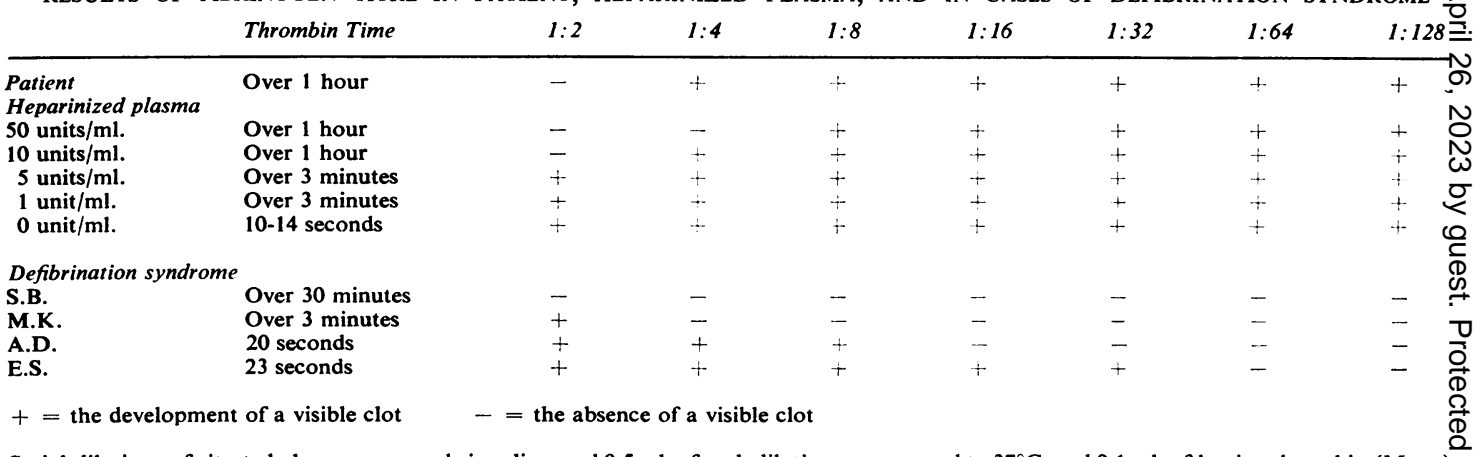

Serial dilutions of citrated plasma were made in saline, and $0.5 \mathrm{ml}$. of each dilution was warmed to $37^{\circ} \mathrm{C}$. and $0.1 \mathrm{ml}$. of bovine thrombin (Maws) 50 units per ml., added. The clotting-time of the 1 in 2 dilution was recorded as the 'thrombin time'. The remaining tubes were incubated foK 15 minutes at $37^{\circ} \mathrm{C}$. and the development of a visible fibrin clot ascertained. The dilution in the last tube showing a clot is the 'fibrinogen titre $\$$ 
than 10 times the concentration needed in the present case.

The cause of the 'heparinaemia' in this patient is obscure. There was no definite evidence of a preexisting bleeding tendency and blood loss at delivery was normal. Haemorrhage first became manifest following a blood transfusion but all tests for incompatibility or bacterial contamination were negative. A shock-like state ensued together with neutropenia. In view of the patient being asthmatic an anaphylactoid reaction to a component of the blood transfusion appears likely. Heparinaemia is known to occur in anaphylaxis (Eagle, Johnston, and Ravdin, 1937).

A small number of obstetric cases developing inhibitors of the thrombin-fibrinogen reaction in association with amniotic fluid embolism, abruptio placentae, septic abortion, or manual removal of the placentae have been reported and are reviewed by Ingram et al. (1960). Baker and Jacob (1960) described a similar state occurring during apparently normal labour and noted that protamine sulphate restored normal clotting in vitro. The evidence that the defect was due to a heparin-like anticoagulant was inconclusive, however, and the authors considered that the abnormality might be due to an alteration in the nature of the patient's fibrinogen. Approximately 100 times greater concentration of protamine was used for maximum correction in vitro than in the case reported here and it is possible that antithrombin VI, rather than heparin, was present in the case of Baker and Jacob. A qualitative abnormality of the patient's fibrinogen is unlikely in the present case since simple dilution in saline restored the clotting of the plasma by thrombin to normal and the Fi test gave a normal result.

Although heparinaemia is rare it is important to include tests that will distinguish this from afibrinogenaemia (Ingram et al., 1960; Ingram, 1961) as the treatment is quite different. Since our experience with this patient we include in the investigation of cases of suspected defibrination syndrome an additional test. When performing the fibrinogen titre and thrombin clotting-time test described by Sharp et al. (1958) we include a mixture of equal parts of patient's and normal citrated plasma and saline serial dilutions thereof. If the clotting time of patient's plasma ( $1: 1$ with saline) is prolonged by virtue of a heparin-like anticoagulant the clotting time of the mixture should also be prolonged. When the cause is a defibrination syndrome, however, it has been found that the clotting time of the mixture is approximately the same as that of normal plasma (1:1 with saline).

In reported cases of spontaneous heparinaemia the parenteral injection of protamine sulphate has not invariably been effective in correcting the blood coagulation even though it does so when added to the patient's plasma in vitro (Castex and Pavlovsky, 1947; Quick and Hussey, 1957). In another case, reported by Bell (1951), in which protamine titration of the patient's plasma indicated $43 \mu \mathrm{g}$. of heparinoid substances per $\mathrm{ml}$., $200 \mathrm{mg}$. of protamine intravenously produced a partial and transitory correction of the clotting time. The present patient had approximately $100 \mu \mathrm{g}$. of heparin-like activity per ml. and showed almost complete correction after $300 \mathrm{mg}$. of protamine followed by $200 \mathrm{mg}$. 10 hours later. This was accompanied by a cessation of clinical bleeding.

I should like to thank Dr. A. M. Sutherland, under whose care this patient was admitted, for permission to report these findings.

Also I am grateful to Dr. G. I. C. Ingram and Dr. A. A. Sharp who kindly read the manuscript.

\section{REFERENCES}

Baker, S. J., and Jacob, E. (1960). J. clin. Path., 13, 214.

Bell, W. N. (1951). Blood, 6, 1199.

Biggs, R., and Macfarlane, R. G. (1957). Human Blood Coagulation and its Disorders, 2nd ed. Blackwell, Oxford.

Castex, M. R., and Pavlovsky, A. (1947). Sang, 18, 1.

Eagle, H., Johnston, C. G., and Ravdin, I. S. (1937). Bull. Johns Hopk. Hosp., 60, 428.

Hardisty, R. M. (1958). Association of Clinical Pathologists Broadsheet No. 19 (N.S.).

Hougie, C. (1955). Brit. med. Bull., 11, 16.

Ingram, G. I. C., (1961). J. clin. Path., 14, 356.

—, and Matchett, M. O. (1960). J. clin. Path., 13, 469.

, Norris, P. R., and Tanner, E. I. (1960). J. Obstet. Gynaec. Brit. Emp., 67, 367.

Jürgens, J., and Stein, F. (1954). Schweiz. med. Wschr., 84, 346.

Krevans, J. R., and Jackson, D. P. (1955). J. Amer. med. Ass., 159, 171.

Larsen, R. A. (1960). Acta med. scand., 167, 171.

Masure, R., and Schockaert, J. A. (1954). Gynaecologia (Basel), 138, 75.

Niewiarowski, S., and Kopec, M. (1961). Hémostase, 1, 237.

Nilsson, I. M., Sjoerdsma, A., and Waldenström, J. (1960). Lancet, 1, 1322.

Quick, A. J., and Hussey, C. V. (1957). Amer. J. med. Sci., 234, 251. Ratnoff, O. D., and Vosburgh, G. J. (1952). Nek Engl. J. Med., 247, 970.

Schneider, C. L. (1951). Surg. Gynec. Obstet., 92, 27.

Sharp, A. A., Howie, B., Biggs, R., and Methuen, D. T. (1958). Lancet, 2, 1309.

Soulier, J. P., Alagille, D., and Larrieı, M. J. (1956). Sem. Hôp. Paris, 32, 359. 